\title{
LGK974 suppresses lipopolysaccharide-induced endotoxemia in mice by modulating the crosstalk between the Wnt/ $\beta$-catenin and NF-KB pathways
}

\author{
Jaewoong Jang ${ }^{1}$, Jaewon Song ${ }^{1}$, Hyunji Lee ${ }^{1}$, Inae Sim', Young V. Kwon'², Eek-hoon Jho $\mathbb{B}^{3}$ and Yoosik Yoon (1)
}

\begin{abstract}
Endotoxemia, a type of sepsis caused by gram-negative bacterial endotoxin [i.e., lipopolysaccharide (LPS)], is associated with manifestations such as cytokine storm; failure of multiple organs, including the liver; and a high mortality rate. We investigated the effect and mechanism of action of LGK974, a Wnt signaling inhibitor, in mice with LPS-induced endotoxemia, an animal model of sepsis. LGK974 significantly and dose-dependently increased the survival rate and reduced plasma cytokine levels in mice with LPS-induced endotoxemia. Transcriptome analysis of liver tissues revealed significant changes in the expression of genes associated with the Wnt pathway as well as cytokine and NF-KB signaling during endotoxemia. LGK974 treatment suppressed the activation of NF-KB signaling and cytokine expression as well as the Wnt/ $\beta$-catenin pathway in the livers of endotoxemic mice. Coimmunoprecipitation of phospho-IKB and $\beta$-transducin repeat-containing protein $(\beta-\operatorname{TrCP})$ was increased in the livers of endotoxemic mice but was reduced by LGK974 treatment. Moreover, LGK974 treatment decreased the coimmunoprecipitation and colocalization of $\beta$-catenin and NF-KB, which were elevated in the livers of endotoxemic mice. Our results reveal crosstalk between the Wnt/ $\beta$-catenin and NF-KB pathways via interactions between $\beta$-TrCP and phospho-IKB and between $\beta$-catenin and NF-KB during endotoxemia. The results of this study strongly suggest that the crosstalk between the Wnt/ $\beta$-catenin and NF-KB pathways contributes to the mutual activation of these two pathways during endotoxemia, which results in amplified cytokine production, liver damage and death, and that LGK974 suppresses this vicious amplification cycle by reducing the crosstalk between these two pathways.
\end{abstract}

\section{Introduction}

Endotoxemia is mediated by the overproduction of proinflammatory cytokines caused by the endotoxin [i.e., lipopolysaccharide (LPS)] of gram-negative bacteria ${ }^{1}$. Under normal physiological conditions, cytokine release is limited to regulate the immune response; however, the endotoxemic state induces unlimited cytokine production, a phenomenon termed "cytokine storm". This phenomenon is mediated by the activation

\footnotetext{
Correspondence: Eek-hoon Jho (ej70@uos.ac.kr) or

Yoosik Yoon (thanks@cau.ac.kr)

'Department of Microbiology, Chung-Ang University College of Medicine, Seoul 06974, Republic of Korea

Department of Biochemistry, University of Washington, Seattle, WA 98195, USA

Full list of author information is available at the end of the article
}

of a cascade that induces autoamplification of cytokine production, which eventually results in multiple organ failure and death ${ }^{2,3}$. Sepsis is defined as life-threatening organ dysfunction caused by a dysregulated host response to infection ${ }^{4}$, whereas endotoxemia is a type of sepsis-induced by infection with gram-negative bacteria ${ }^{5}$. The prevalence of endotoxemia is as high as to $82 \%$ in patients with sepsis ${ }^{6}$. Therefore, mice with LPSinduced endotoxemia have been used as an animal model of sepsis ${ }^{7-10}$.

Liver dysfunction caused by bacteria and endotoxin is an essential event in sepsis accompanied by cytokine storm $^{11}$. Elevated cytokine expression in the liver is a marker of sepsis ${ }^{12}$, and sepsis-induced liver dysfunction increases mortality ${ }^{13}$; therefore, attenuation of liver injury

\section{(c) The Author(s) 2021}

(c) Open Access This article is licensed under a Creative Commons Attribution 4.0 International License, which permits use, sharing, adaptation, distribution and reproduction cc) in any medium or format, as long as you give appropriate credit to the original author(s) and the source, provide a link to the Creative Commons license, and indicate if changes were made. The images or other third party material in this article are included in the article's Creative Commons license, unless indicated otherwise in a credit line to the material. If material is not included in the article's Creative Commons license and your intended use is not permitted by statutory regulation or exceeds the permitted use, you will need to obtain permission directly from the copyright holder. To view a copy of this license, visit http://creativecommons.org/licenses/by/4.0/. 
and restoration of liver function significantly lower the mortality risk of patients with sepsis ${ }^{14}$.

Recently, Wnt signaling has been reported to be involved in inflammation and sepsis. Microbial stimulation of human mononuclear cells induces WNT5A, which upregulates the expression of proinflammatory cytokines, including IL-6 and IL- $1 \beta^{15}$. An inhibitor of $\beta$-cateninmediated transcription, iCRT3, was reported to reduce LPS-induced WNT signaling and proinflammatory cytokine production ${ }^{16}$. It was reported that WNT5A levels were significantly increased in the sera of patients with sepsis ${ }^{17}$ and that multiple WNT ligands were expressed in the peripheral blood of patients with septic shock ${ }^{18}$. However, the crosstalk between the Wnt/ $\beta$-catenin and NF- $\kappa B$ pathways has not yet been elucidated in the context of sepsis. In this study, we analyzed the effects of LGK974, a Wnt signaling inhibitor, in LPS-induced endotoxemic mice through analyses of the crosstalk between the $\mathrm{Wnt} / \beta$-catenin and NF- $\mathrm{BB}$ pathways in the liver as well as the effects of this crosstalk on the survival rate and induction of cytokine storm.

LGK974 has been developed as a candidate anticancer drug against Wnt-driven cancers ${ }^{19}$; it has shown suppressive effects against ovarian cancer ${ }^{20}$, lung cancer $^{21}$, squamous cell carcinoma ${ }^{22,23}$, glioblastoma ${ }^{24,25}$, and colon cancer ${ }^{26}$. It is currently in phase 1 clinical trial in patients with colorectal cancer ${ }^{27}$. Other effects of this Wnt signaling inhibitor have also been reported; LGK974 has been shown to ameliorate cystogenesis in a mouse model of polycystic kidney disease ${ }^{28}$. We previously reported that LGK974 exerts anti-inflammatory effects in LPS-stimulated human bronchial epithelial cells and human umbilical vein endothelial cells ${ }^{29}$. However, no studies have investigated its effects on sepsis. Sepsis is the most common cause of death among critically ill patients in noncoronary intensive care units, and there is an urgent need for an effective treatment for sepsis ${ }^{30}$. Thus, in the present study, we examined the effect and mechanism of action of LGK974 in mice with LPS-induced endotoxemia, an animal model of sepsis.

\section{Materials and methods Reagents}

Anti-IкB (cat\# 9242), anti-phospho-IкB (Ser 32/36) (cat\# 9246), anti-NF-kB p65 (cat\# 8242), anti-GSK3ß (cat\# 9315), anti-phospho-GSK3 $\beta$ (Ser 9) (cat\# 9336), antiAXIN (cat\# 2087), anti-LRP6 (cat\# 3395), anti-phosphoLRP6 (Ser 1490) (cat\# 2568), and anti- $\beta$-TrCP (cat\# 4394S) primary antibodies, as well as anti-mouse (cat\# 7076S) and anti-rabbit (cat\# 7074S) secondary antibodies, were purchased from Cell Signaling Technology (Danvers, MA, USA). An anti- $\beta$-catenin antibody (cat\# 610153) was purchased from $\mathrm{BD}$ Transduction Laboratories Inc. (Lexington, KY, USA). Anti- $\beta$-actin (cat\# 47778) and
anti-TBP (cat\# 204) antibodies were purchased from Santa Cruz Biotechnology Inc. (Santa Cruz, CA, USA). LPS from Klebsiella pneumoniae was purchased from Sigma-Aldrich (St. Louis, MO, USA). LGK974 was obtained from MedChemExpress (Monmouth Junction, NJ, USA).

\section{Animal experiments}

Animal experimental protocols were approved by the institutional animal care and use committee of ChungAng University (approval numbers 2017-00099 and 201800042), and all experiments were performed in accordance with the animal research: reporting of in vivo experiments guidelines. Male C57BL/6 mice (4 weeks old) were purchased from Central Lab Animal Inc. (Seoul, Republic of Korea). LGK974 was injected i.p. $2 \mathrm{~h}$ before i.p. injection of LPS in most experiments. For survival experiments, various doses of LGK974 were injected $2 \mathrm{~h}$ before, simultaneously with, or $1 \mathrm{~h}$ after LPS injection. For another survival experiment, various doses of LGK974 were injected simultaneously with Escherichia coli ( $E$. coli). E. coli strain $\mathrm{K} 12$ was cultured overnight in LB broth, and cell numbers were determined based on the optical density at $600 \mathrm{~nm}$. Then, $10^{11}$ colony-forming units (CFUs) of $E$. coli were resuspended in $200 \mu \mathrm{l}$ of saline immediately before i.p. injection. Both LGK974 and LPS were dissolved in saline by vigorous vortexing immediately before injection. Saline-injected mice served as a control group. Mice were anesthetized via i.p. injection of $10 \mathrm{mg} / \mathrm{kg}$ alfaxalone (Jurox, Rutherford, Australia) $6 \mathrm{~h}$ after LPS injection. Liver tissue was collected and stored at $-70^{\circ} \mathrm{C}$ for further analyses. Blood samples were collected in EDTA tubes and were then centrifuged at $2000 \times g$ for $10 \mathrm{~min}$ to collect plasma. A magnetic Luminex assay with antibody-based 9-plex immunoassays (Luminex, Austin, TX, USA) was used to measure the plasma concentrations of selected cytokines, including TNF- $\alpha, \quad$ IL-6, IL-1 $\beta$, IL-1 $\alpha$, IL-12, IFN- $\gamma$, MCP-1, RANTES, and IL-10. Measurements were performed using a Magpix Luminex instrument (Luminex) and MasterPlex QT 2010 software (MiraiBio, San Francisco, CA, USA).

\section{RNA-seq and gene set enrichment analysis (GSEA)}

RNA samples extracted from the livers of mice were analyzed by RNA-seq, and the original raw data have been deposited in the NCBI Gene Expression Omnibus database under accession number GSE127459 (https://www. ncbi.nlm.nih.gov/geo/query/acc.cgi?acc=GSE127459).

GSEA was conducted to compare the RNA-seq data sets. The primary result of GSEA is an enrichment score (ES), which indicates the degree to which a gene set is overrepresented among upregulated genes or downregulated genes in a ranked list of genes in the expression data set. A positive ES indicates enrichment of the gene 
set among the upregulated genes in the ranked list; a negative ES indicates enrichment of the gene set among the downregulated genes in the ranked list. The normalized ES (NES) is the ES for the gene set after normalization across all analyzed gene sets. The significance ( $P$ value) of the NES is primarily affected by the false discovery rate, which is the probability that a gene set with a given NES represents a false-positive finding (http:// software.broadinstitute.org/gsea/index.jsp) ${ }^{31}$.

\section{Quantitative reverse-transcription (RT-q)PCR}

Total RNA was isolated from liver tissue using an RNeasy Kit (Qiagen; Cat. No. 74106) in a homogenizer. One microgram of RNA was reverse transcribed using a cDNA Reverse Transcription Kit (Applied Biosystems Inc.; Cat. No. 43-688-13). RT-qPCR was conducted as described previously ${ }^{29}$. Assay-on-Demand gene expression products (Applied Biosystems, Inc., Foster City, CA, USA) were used for RT-qPCR to evaluate the mRNA levels of Tnf (Mm00443258_m1), Il6 (Mm00446190_m1), Il1b (Mm00434228_m1), Il1a (Mm00439620_m1), Wnt3a (Mm00437337_m1), Wnt5a (Mm00437347_m1), Wnt10a (Mm00437325_m1), and Wnt10b (Mm00442104_m1). For each experimental group, the mRNA levels were normalized to the $18 \mathrm{~S}$ ribosomal RNA level, and the ratios of the normalized mRNA levels in each group were compared to those in the control group using the comparative Ct method ${ }^{32}$.

\section{Protein extraction and western blotting}

Liver tissues were lysed in a homogenizer using RIPA buffer containing $25 \mathrm{mM}$ Tris- $\mathrm{HCl}(\mathrm{pH} 7.6), 150 \mathrm{mM}$ $\mathrm{NaCl}, 1 \%$ Nonidet P-40, $1 \%$ sodium deoxycholate, $0.1 \%$ sodium dodecyl sulfate, and protease inhibitor cocktail (Sigma-Aldrich; Cat. No. P8340) for $30 \mathrm{~min}$ at $4{ }^{\circ} \mathrm{C}$. Total tissue lysates were obtained after removing the insoluble material by centrifugation at $20,000 \times g$ for $20 \mathrm{~min}$ at $4{ }^{\circ} \mathrm{C}$. Nuclear lysates were collected from liver tissue using a nuclear extraction kit (Active Motif, Carlsbad, CA, USA). Protein concentrations were determined using a BCA protein assay kit (Pierce, Waltham, MA, USA), and $10-100 \mu \mathrm{g}$ of protein was analyzed by western blotting as described previously ${ }^{29}$. $\beta$-Actin and TATA box-binding protein (TBP) were used as loading controls for total tissue lysates and nuclear lysates, respectively. Band intensities-corresponding to protein expression levelswere quantified by ImageJ (NIH, Bethesda, MD, USA) and normalized to those of the loading controls.

\section{Target DNA-binding activity of NF-KB}

Nuclear fractions were collected from frozen tissues using a nuclear extraction kit (Active Motif, Carlsbad, CA, USA), and protein concentrations were determined using a BCA protein assay kit (Pierce). The binding affinity of
NF- $\kappa \mathrm{B}$ to its target DNA sequence (5'-GGGACTTTCC$3^{\prime}$ ) was measured using a TransAM NF-kB ELISA Kit (Active Motif) according to the manufacturer's instructions. Briefly, $10 \mu \mathrm{g}$ of protein (nuclear fraction) was added to a 96-well plate coated with oligonucleotides containing the target DNA sequence. After incubation and washing, an anti-NF- $\mathrm{kB}$ antibody was added to the wells, followed by the horseradish peroxidase-conjugated secondary antibody provided in the kit. The absorbance at $450 \mathrm{~nm}$ was measured after sequential addition of the developing solution and the stop solution provided in the kit.

\section{Coimmunoprecipitation assay for protein-protein binding interactions}

Coimmunoprecipitation experiments were performed using an immunoprecipitation kit from BioVision (Mountain View, CA, USA) according to the manufacturer's instructions. Frozen tissues were lysed in a homogenizer using a nondenaturing lysis buffer provided in the kit at $4{ }^{\circ} \mathrm{C}$ for $30 \mathrm{~min}$ and were then centrifuged at $10,000 \times g$ for $10 \mathrm{~min}$ at $4{ }^{\circ} \mathrm{C}$. The supernatant was supplemented with $2 \mu \mathrm{g} / \mathrm{ml}$ of an antibody specific for the bait protein and incubated overnight at $4{ }^{\circ} \mathrm{C}$. After adding $25 \mu \mathrm{l}$ of protein A/G bead slurry and incubating for $1 \mathrm{~h}$ at $4^{\circ} \mathrm{C}$, the beads were collected by centrifugation at $2000 \times g$ for $2 \mathrm{~min}$. The collected beads were washed three times with $1 \mathrm{ml}$ of wash buffer provided with the kit and mixed with $40 \mu \mathrm{l}$ of $2 \times$ sodium dodecyl sulfate-polyacrylamide gel electrophoresis loading buffer. The amount of target protein bound to the beads was measured by western blotting with an antibody specific for the target protein. Band intensities were quantified using Image $(\mathrm{NIH}$, Bethesda, MD, USA).

\section{Confocal microscopy for evaluation of protein colocalization}

Tissue preparation and confocal microscopy were conducted as described previously with some modifications ${ }^{33}$. Liver tissues were snap-frozen and embedded in OCT compound (Sakura, Tokyo, Japan). Embedded tissues were cryosectioned at a thickness of $10 \mu \mathrm{m}$. For immunofluorescence, sections were fixed with cold acetone for $10 \mathrm{~min}$ and incubated first in blocking buffer (CAS-Block; Thermo Fisher Scientific) for $1 \mathrm{~h}$ and then with a mouse anti- $\beta$-catenin antibody (Transduction Laboratory, \#610153; 1:200) and a rabbit anti-NF-kB p65 antibody (Cell Signaling Technology \#8242, 1:200) in phosphatebuffered saline (PBS) overnight. Sections were washed three times in PBS containing 0.03\% Triton X-100 and incubated with a Cy3-labeled donkey anti-mouse IgG antibody (cat\# 715-165-150, Jackson ImmunoResearch Laboratories, Inc., West Grove, PA, USA, 1:400) and FITC-labeled donkey anti-rabbit IgG (cat\# 715-095-152, 
Jackson ImmunoResearch Laboratories, Inc., 1:400) in PBS for $1 \mathrm{~h}$. After counterstaining with $1 \mu \mathrm{g} / \mathrm{ml}$ DAPI (cat\# D9542, Sigma-Aldrich), the tissues were mounted and visualized under a confocal microscope (Nikon A1Si, Nikon, Tokyo, Japan). Images from different experimental groups were acquired under the same exposure and detection settings. Colocalization of fluorescence signals was analyzed using ImageJ.

\section{Statistical analysis}

All data are expressed as the mean \pm standard deviation values. Differences among experimental groups were analyzed using one-way ANOVA with Duncan's multiple range test. $P<0.05$ was considered significant. All analyses were performed using SPSS ver. 14 (SPSS, Chicago, IL, USA).

\section{Results and discussion}

LPS-induced endotoxemic mice show dose-dependent lethality and cytokine storm

LPS decreased the survival rate of C57BL/6 mice in a dose-dependent manner (Fig. 1a). To evaluate whether LPS-induced endotoxemia induces cytokine storm in mice, the concentrations of plasma cytokines were measured after the injection of LPS at various doses (Fig. 1b-j). The plasma concentrations of TNF- $\alpha$, IL-6, IL$1 \beta$, IL-1 $\alpha$, IL-12, INF- $\gamma$, MCP-1, RANTES, and IL-10 were markedly and dose-dependently increased in mice injected with $1-25 \mathrm{mg} / \mathrm{kg}$ LPS. As the highest plasma cytokine levels were observed after injection of $25 \mathrm{mg} / \mathrm{kg}$ LPS, this dose was used to induce endotoxemia in subsequent experiments.

\section{LGK974 improves the survival rate and suppresses} cytokine storm in mice with LPS-induced endotoxemia

We analyzed the effect of LGK974 on the survival rate of mice with LPS-induced endotoxemia (4-week-old male mice). The survival rate of mice that received $25 \mathrm{mg} / \mathrm{kg}$ LPS alone was $0 \%$. Mice treated with 20 and $40 \mathrm{mg} / \mathrm{kg}$ LGK974 before LPS injection exhibited survival rates of 20 and $80 \%$, respectively, whereas mice treated with $60 \mathrm{mg} / \mathrm{kg}$ LGK974 had a 100\% survival rate (5 mice per group) (Fig. 2a). It should be noted that LGK974 increased the survival rate of mice with LPS-induced endotoxemia regardless of whether it was administered simultaneously with LPS injection (Fig. 2b) or after LPS injection (Fig. 2c). Moreover, LGK974 increased the survival rate of mice injected with viable $E$. coli cells (Fig. 2d). Overall, these results showed that LGK974 improved the survival rate of mice in which sepsis was induced by injection of endotoxin or bacteria in a dose-dependent manner. We also conducted survival experiments in 4-week-old female mice and 13-week-old male mice (Supplementary Data 1). LGK974 increased the survival rate in both experiments, suggesting that the protective effect of LGK974 may be independent of the sex and age of the mice. The effects of LGK974 on mice older than 13 weeks remain to be investigated in further studies.

When mice were injected with $0-60 \mathrm{mg} / \mathrm{kg}$ LGK974 and $25 \mathrm{mg} / \mathrm{kg} \mathrm{LPS}$, the levels of proinflammatory cytokines, including TNF- $\alpha$, IL-6, IL- $1 \beta$, IL- $1 \alpha$, IL-12, INF- $\gamma$, MCP-1, and RANTES, were significantly and dosedependently downregulated by LGK974 (Fig. 2e-1). However, the level of IL-10 was not altered upon LGK974 treatment (Fig. $2 \mathrm{~m}$ ). IL-10 is a potent anti-inflammatory cytokine that plays a central role in limiting the host immune response, thereby preventing damage to host tissues $^{34}$. The effects of LGK974 on other antiinflammatory cytokines remain to be elucidated. Our data suggest that LGK974 has a suppressive effect on proinflammatory cytokine production in mice with LPSinduced endotoxemia.

\section{RNA-seq and GSEA of liver tissue reveal significant changes in the expression of genes in the Wnt pathway as well as cytokine and NF-KB signaling during LPS-induced endotoxemia}

Among the multiple organs damaged in endotoxemia, we focused on the liver, as liver dysfunction caused by bacteria or endotoxin has been shown to be an essential event in sepsis, along with cytokine storm ${ }^{11}$. RNA-seq experiments were conducted to analyze gene expression patterns in liver tissues from saline-injected mice (control group) and mice injected with $25 \mathrm{mg} / \mathrm{kg}$ LPS (endotoxemic group) or with $60 \mathrm{mg} / \mathrm{kg}$ LGK974 and $25 \mathrm{mg} / \mathrm{kg}$ LPS (LGK974 group). The complete set of RNA-seq data, including fold changes, $P$ values, and expression levels for more than 23,000 genes, are presented in Supplementary Data 2 (RNA-seq data).

GSEA showed that many gene ontology (GO) terms related to cytokines, NF- $\mathrm{kB}$ signaling, and the Wnt pathway were significantly altered in the liver upon LPS and LGK974 treatment; among these alterations, the changes in three GO terms are illustrated in Fig. 3, and the complete set of GSEA data for all GO terms is shown in Supplementary Data 3 (GSEA data). Most of the GO terms related to cytokine and NF- $\mathrm{kB}$ signaling were overrepresented in the endotoxemic group compared with the control group. The GO terms "cytokine activity" and "ІкB kinase NF- $\kappa B$ signaling" are illustrated in Fig. 3a, b. Among the GO terms related to the Wnt pathway, the GO term "negative regulation of Wnt signaling pathway" was significantly underrepresented (Fig. 3c), while the GO term "positive regulation of Wnt signaling pathway" was not significantly changed (Supplementary Data 3 (GSEA data)). The GO terms "cytokine activity" and "IKB kinase NF- $\mathrm{B}$ signaling" were significantly underrepresented, whereas the GO term "negative regulation of Wnt 
a
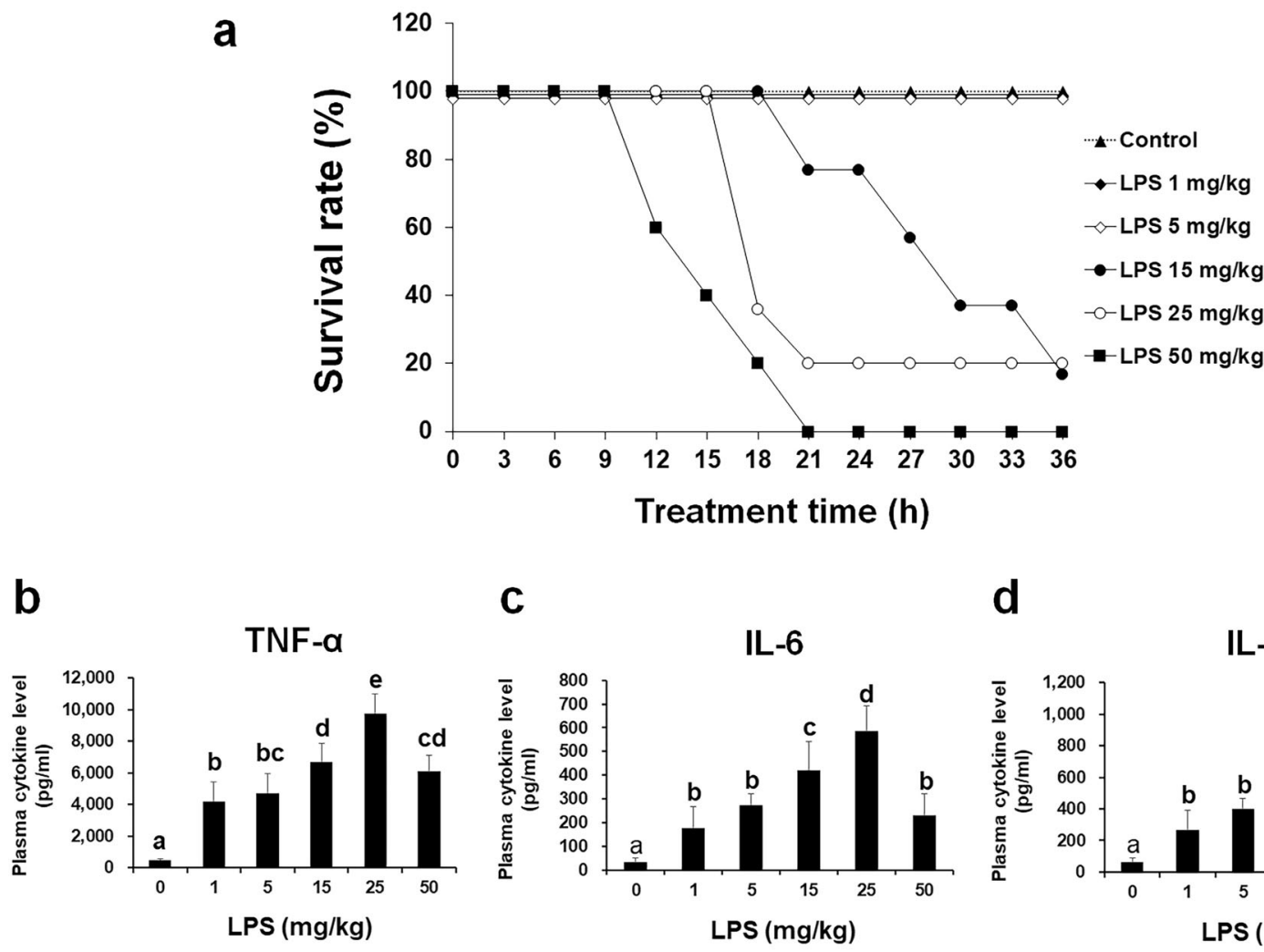

C

d

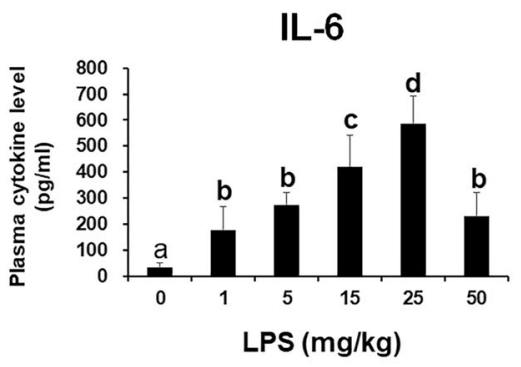

IL-1 $\beta$

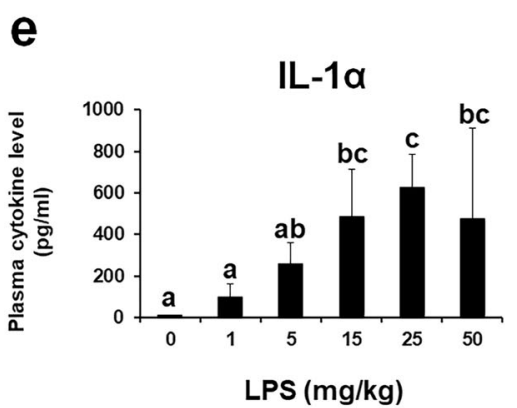

f

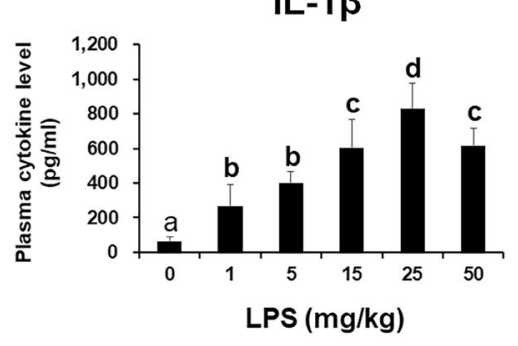

IL-12

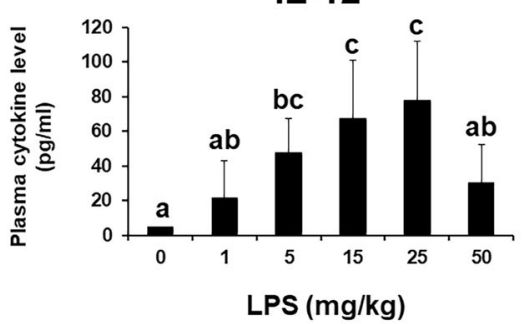

g
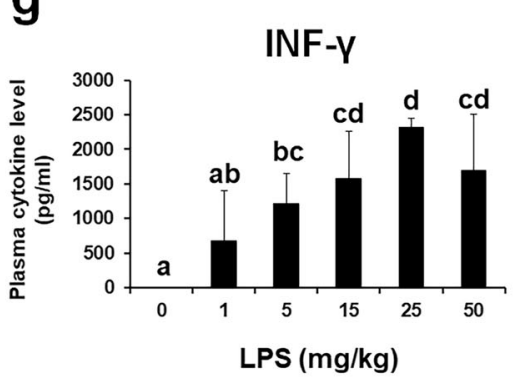

h

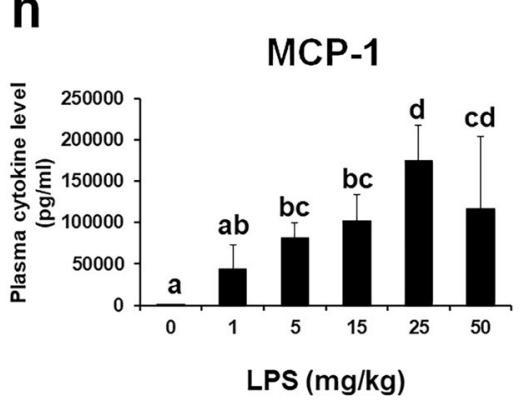

i

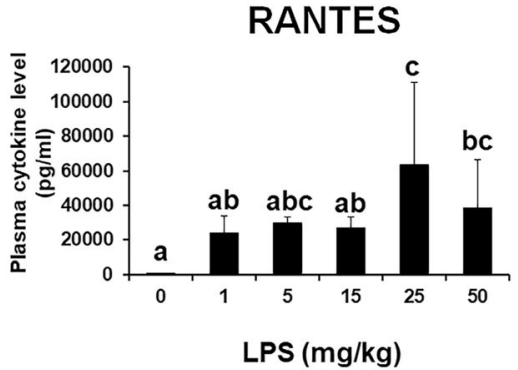

j

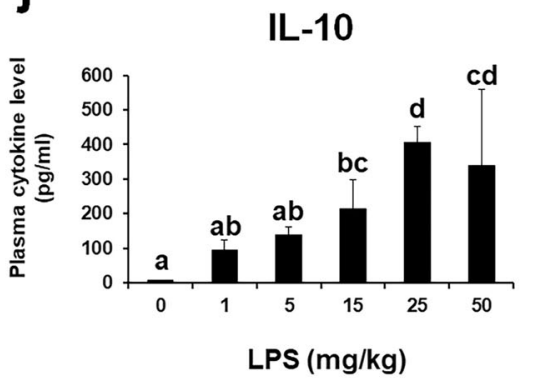

Fig. 1 Survival rates and plasma cytokine levels in mice with LPS-induced endotoxemia. C57BL/6 mice were injected i.p. with 1-50 mg/kg LPS dissolved in saline. Mice in the control group were injected with the same volume of saline. a Survival in each group was monitored at 3-h intervals $(n=5)$. b-j Cytokine concentrations in plasma collected from mice were measured using a magnetic Luminex assay. The data are presented as the mean \pm standard deviation values $(n=7)$. Differences among experimental groups were analyzed using one-way ANOVA with Duncan's multiple range test. The different letters indicate significant differences ( $(*<0.05)$. 

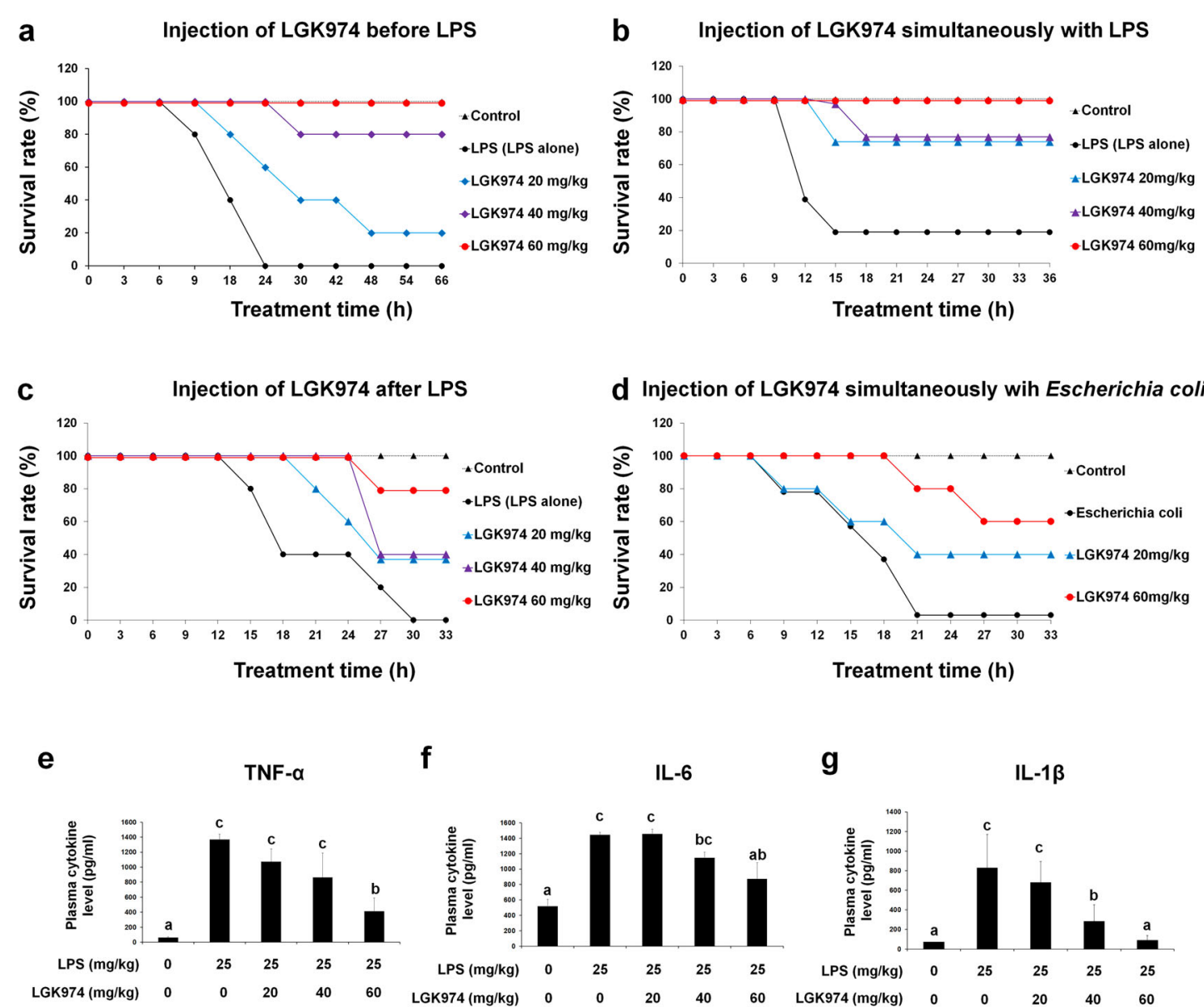

f

IL-6

g

IL-1 $\beta$

h

IL-1a
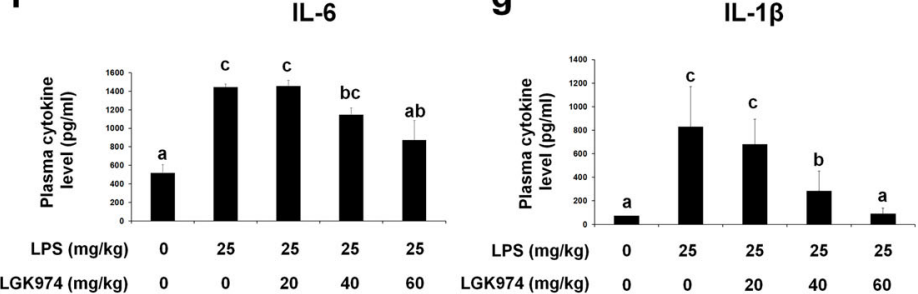

i

IL-12

j

INF-Y
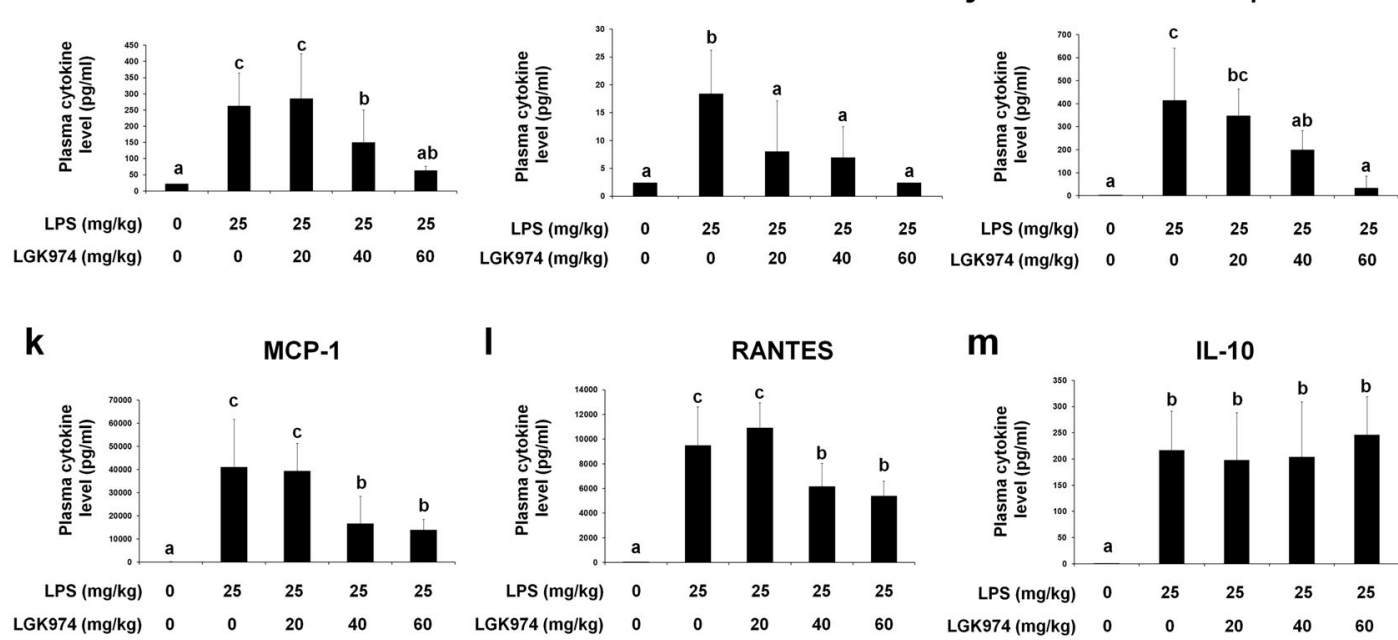

I

RANTES
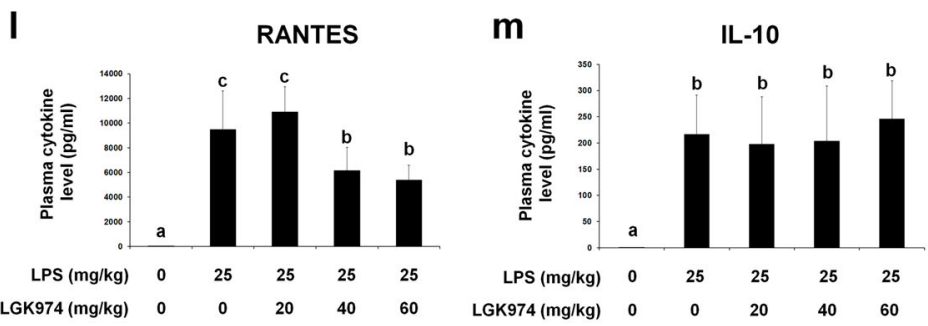

Fig. 2 Effect of LGK974 on the survival rate and cytokine storm in endotoxemic mice. a-d Effect of LGK974 on the survival rate in various endotoxemic mouse models $(n=5)$. LGK974 (0-60 mg/kg) was injected i.p. a $2 \mathrm{~h}$ before, $\mathbf{b}$ simultaneously with, and $\mathbf{c} 1 \mathrm{~h}$ after i.p. injection of $25 \mathrm{mg} /$ $\mathrm{kg}$ of LPS. $\mathbf{d}$ LGK974 (0-60 mg/kg) was injected i.p. simultaneously with $10^{11}$ CFU of viable Escherichia coli cells. Mice in the control group were injected with the same volume of saline. e-m LGK974 suppresses cytokine storm in endotoxemic mice. C57BL/6 mice were injected i.p. with 0-60 mg/kg LGK974 $2 \mathrm{~h}$ before being injected with $25 \mathrm{mg} / \mathrm{kg}$ LPS. Cytokine concentrations in the plasma were determined using a magnetic Luminex assay. The data are presented as the mean \pm standard deviation values $(n=7)$. Differences among experimental groups were analyzed using one-way ANOVA with Duncan's multiple range test. The different letters indicate significant differences $\left({ }^{*} P<0.05\right)$. 


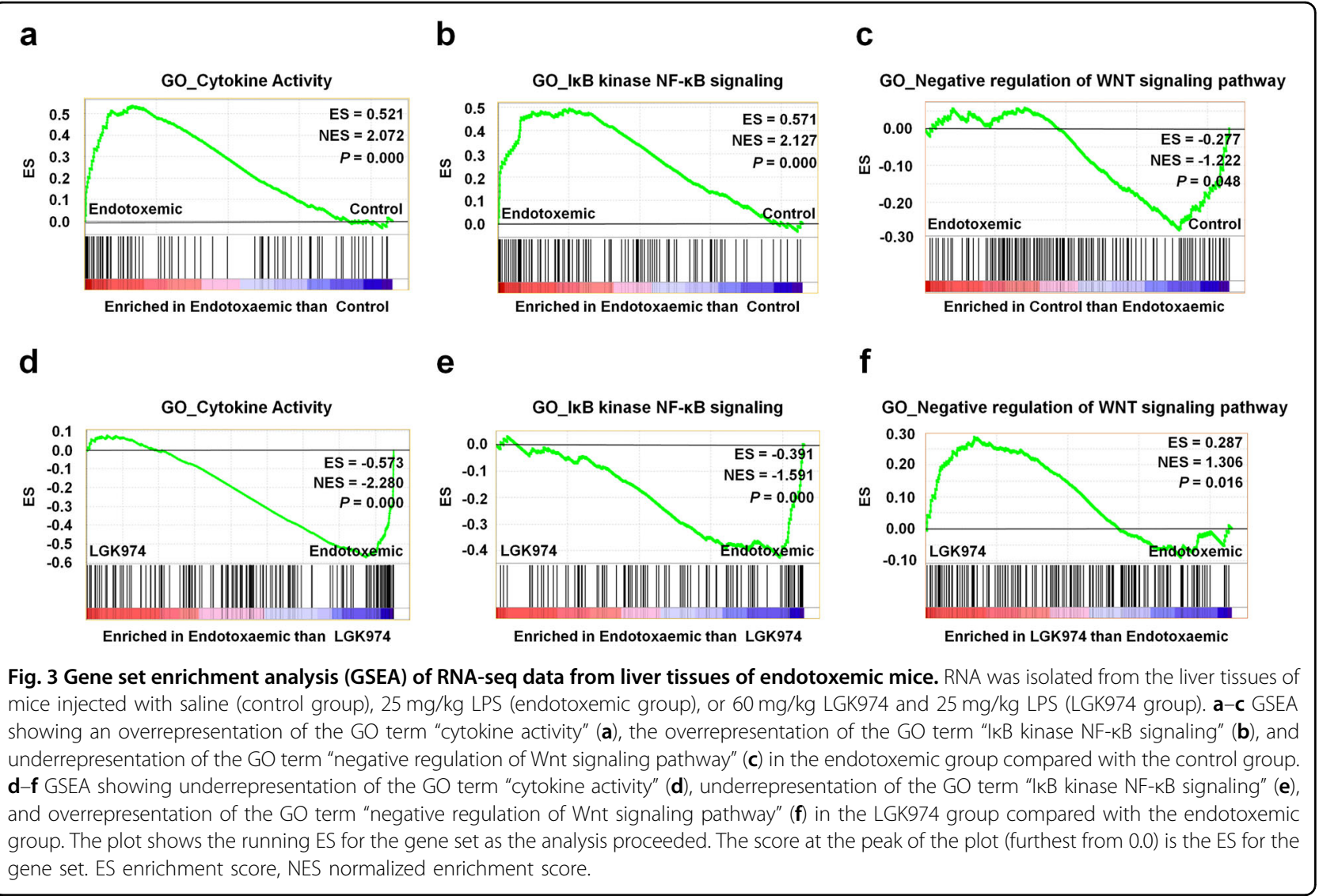

signaling pathway" was significantly overrepresented in the LGK974 group compared with the endotoxemic group (Fig. 3d-f). The list of genes in these selected GO terms is shown in Supplementary Data 4 (List of genes in selected GO terms). Collectively, these results suggested that the levels of transcripts associated with the Wnt pathway as well as with NF- $\mathrm{kB}$ signaling and cytokines were significantly changed in the livers of LPS-induced endotoxemic mice and that these changes were suppressed by LGK974 treatment.

NF-KB signaling and cytokine expression are accompanied by Wnt signaling activation in the livers of mice with LPSinduced endotoxemia

To confirm the findings of RNA-seq and GSEA, western blot and RT-qPCR experiments were conducted. Proteins were extracted from the livers of mice injected with 0,5 , or $25 \mathrm{mg} / \mathrm{kg}$ LPS and analyzed by western blotting (Fig. 4a). All original western blot images are provided in Supplementary Data 5. In the livers of mice with LPSinduced endotoxemia, phosphorylation of I $\mathrm{K} B$ increased, whereas the amount of ІкB decreased (Fig. $4 \mathrm{a}-\mathrm{c}$ ). Moreover, the nuclear levels of NF-kB (Fig. 4a, d) and the target DNA-binding activity of NF- $\mathrm{kB}$ (Fig. 4e) were increased. $\mathrm{NF}-\kappa \mathrm{B}$ is a major proinflammatory transcription factor that binds to the regulatory region of genes encoding proinflammatory cytokines, thus inducing proinflammatory cytokine expression ${ }^{35,36}$. The relative mRNA expression levels of Tnf, Il6, Ilb, and Ila (the genes encoding TNF- $\alpha$, IL- 6 , IL- $1 \beta$, and IL- $1 \alpha$, respectively) were significantly increased by LPS in a dose-dependent manner (Fig. 4f-i).

As the GSEA results suggested that Wnt signaling in the liver was significantly changed during endotoxemia, we analyzed this pathway in detail. The mRNA levels of Wnt genes such as Wnt3a, Wnt5a, Wnt10a, and $W n t 10 b$ were significantly increased by LPS in a dosedependent manner (Fig. $4 \mathbf{j}-\mathrm{m}$ ). The protein levels of phospho-lipoprotein receptor-related protein 6 (LRP6) (Fig. $4 \mathrm{n}, \mathrm{o}$ ), and phospho-glycogen synthase kinase- $3 \beta$ $($ GSK-3 $\beta$ ) (Fig. $4 \mathrm{n}$ ), two positive regulators of Wnt signaling, were increased by LPS. Conversely, AXIN, a negative regulator of Wnt signaling, was downregulated (Fig. $4 \mathrm{n}, \mathrm{p}$ ). $\beta$-Catenin, the executor protein of Wnt signaling, was significantly upregulated (Fig. 4n, q). Similarly, the expression of $\beta$-transducin repeatcontaining protein $(\beta-\operatorname{TrCP})$, which is one of the target genes of $\beta$-catenin ${ }^{37}$, was upregulated (Fig. $4 \mathrm{n}, \mathrm{r}$ ). Taken together, the above results confirmed that NF- $\mathrm{kB}$ signaling, cytokine expression, Wnt ligand expression, 


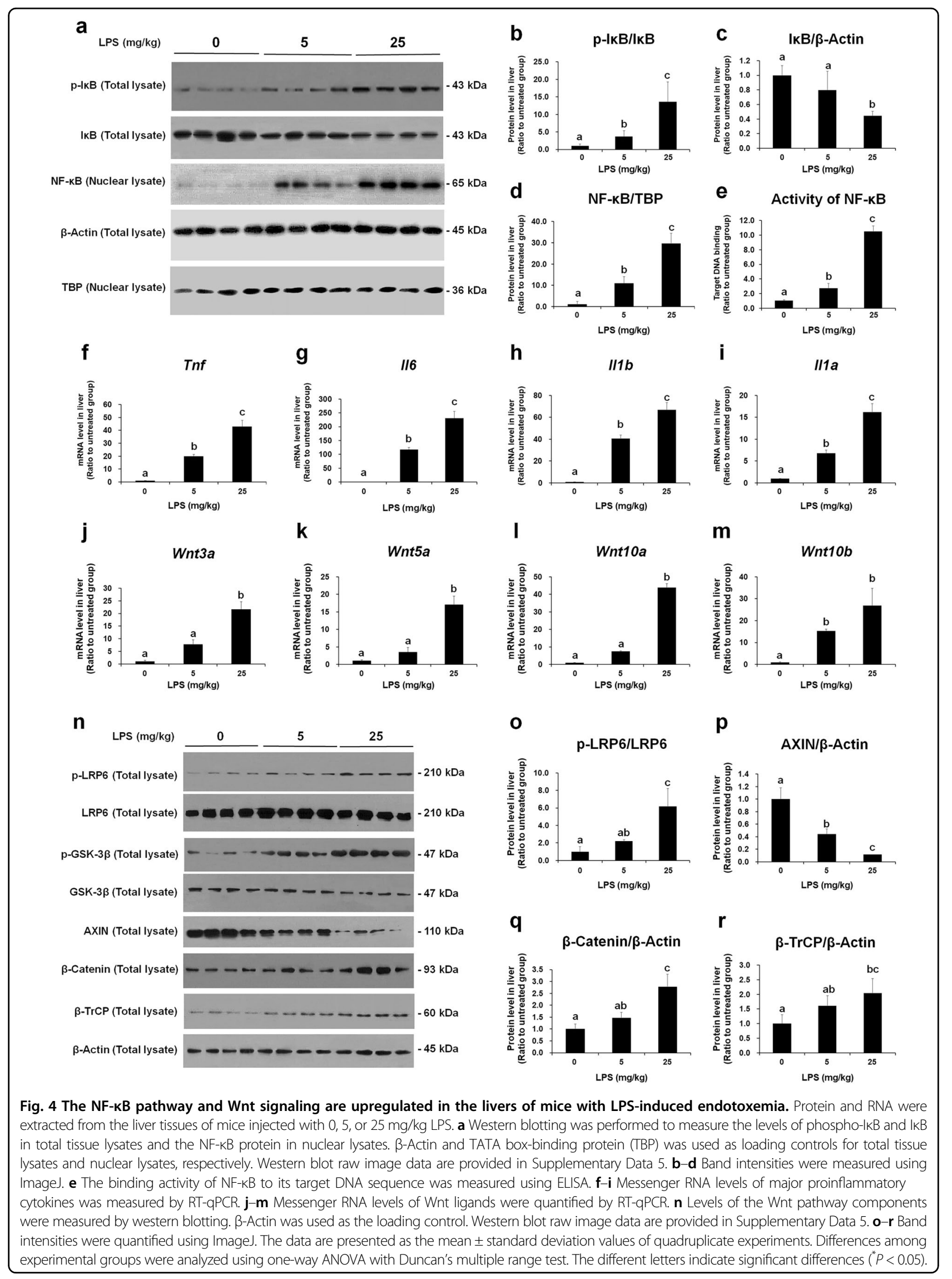


and the Wnt/ $\beta$-catenin pathway were upregulated in the livers of mice with LPS-induced endotoxemia. It has been reported that transcripts of some Wnt ligands, including WNT5A and WNT10B, were induced by NF$\mathrm{\kappa B}^{38-40}$, and the promoters of WNT5A and WNT10B were found to contain NF-KB-binding sites ${ }^{41,42}$. We suggest that the LPS-induced Wnt ligand expression and Wnt pathway activation during LPS-induced endotoxemia (Fig. $4 \mathrm{j}-\mathrm{r}$ ) may be attributed to increased NF- $\mathrm{kB}$ signaling and its target DNA binding activity (Fig. 4a-e).

\section{LGK974 suppresses Wnt/ $\beta$-catenin signaling, NF-KB signaling, and cytokine expression in the livers of mice with LPS-induced endotoxemia}

We evaluated whether the Wnt signaling inhibitor LGK974 can modulate $\mathrm{Wnt} / \beta$-catenin signaling, NF- $\mathrm{KB}$ signaling, and cytokine expression in the livers of endotoxemic mice. Mice were injected i.p. with 0 or $60 \mathrm{mg} / \mathrm{kg}$ LGK 974 and 0 or $25 \mathrm{mg} / \mathrm{kg}$ LPS. Protein and RNA were then extracted from the livers of the mice, and the expression of components of the $\mathrm{Wnt} / \beta$-catenin pathway was analyzed by western blotting and RT-qPCR. The results confirmed the GSEA data (Fig. 3f), showing that upregulated Wnt signaling in the livers of endotoxemic mice was inhibited by LGK974. The levels of phosphoLRP6 and phospho-GSK-3 $\beta$, which were increased by LPS, were significantly reduced after LGK974 treatment (Fig. 5a, b). The total tissue and nuclear levels of $\beta$-catenin, the executor protein of the Wnt signaling pathway, were reduced by LGK974 (Fig. 5a, c, d). In addition, the level of $\beta$-TrCP, a target gene of $\beta$-catenin ${ }^{37}$, was reduced by LPK974 (Fig. 5a, e). The mRNA levels of Wnt3a, Wnt5a, Wnt10a, and Wnt10b in the livers of endotoxemic mice were reduced by LGK974 treatment (Fig. 5f-i). LGK974 alone had no effect on Wnt signaling. The dose-dependent effects of LGK974 on Wnt signaling in the livers of endotoxemic mice are shown in Supplementary Data 6.

Next, using the same liver protein and RNA samples, we analyzed the expression of NF- $\mathrm{kB}$ pathway components and proinflammatory cytokines. The phospho-ІкB level was decreased by LGK974 (Fig. 6a, b). The level of cytoplasmic NF- $\mathrm{KB}$ was increased but that of nuclear NF- $\mathrm{KB}$ was decreased by LGK974 (Fig. 6a, c, d). The binding affinity of NF- $\mathrm{KB}$ for its target DNA was significantly decreased by LGK974 (Fig. 6e), as were the transcript levels of genes encoding proinflammatory cytokines, such as Tnf, Il6, Ilb, and Ila (Fig. $6 \mathrm{f}-\mathrm{i}$ ). When mice were treated with LGK974 alone, no significant changes were observed in this group compared with the saline-treated control group. The dose-dependent effects of LGK974 on NF-kB signaling and proinflammatory cytokine expression are shown in Supplementary Data 7.
LGK974 reduces the interaction between phospho-IKB and $\beta$-TrCP in the livers of mice with LPS-induced endotoxemia

We found that the protein-protein interaction between phospho-IкB and $\beta$-TrCP identified by coimmunoprecipitation was increased in mice with LPS-induced endotoxemia and decreased by LGK974 treatment (Fig. 6j). Western blot analysis of the input samples from the coimmunoprecipitation experiment showed that the protein levels of both $\beta$-TrCP and phospho-IкB were increased by LPS and decreased by LGK974 (Fig. 6k), the same pattern as that shown in Fig. 5e and Fig. 6b. Our data showed that the level of the protein-protein interaction between $\beta$-TrCP and phospho-IкB was proportional to the levels of these proteins in the livers of endotoxemic mice, which were reduced by LGK974.

To date, the interaction between $\beta-\operatorname{TrCP}$ and phosphoIKB has not been reported in the context of endotoxemia or sepsis. $\beta$ - TrCP is a component of the IкB-ubiquitin ligase that induces the ubiquitination of phospho-IK $\mathrm{B}^{43-45} ; \beta-\operatorname{Tr} C \mathrm{P}$ is a rate-limiting mediator that regulates the degradation of phospho-ІкB, with increased binding resulting in increased degradation $^{46}$. We suggest that the increased levels of $\beta$-TrCP and phospho-IкB and the interaction between these two proteins may induce ІкB degradation followed by NF$\mathrm{\kappa B}$ nuclear translocation and proinflammatory cytokine expression in the livers of endotoxemic mice.

\section{LGK974 reduces the interaction between $\beta$-catenin and NF-} $K B$ in the livers of mice with LPS-induced endotoxemia

$\beta$-Catenin is the major effector protein of the Wnt/ $\beta$-catenin pathway. When this pathway is inactive, $\beta$-catenin is phosphorylated by GSK-3 $\beta$ in a complex containing AXIN and adenomatous polyposis coli (APC) for subsequent proteolysis. Alternatively, when this pathway is active, phosphorylated LRP5/6 recruits AXIN and disrupts the GSK-3 $\beta$-AXIN-APC complex, subsequently dephosphorylating and stabilizing $\beta$-catenin ${ }^{47}$. Because the levels of the $\mathrm{Wnt} / \beta$-catenin and NF- $\mathrm{KB}$ signaling components were modulated by LPS and LGK974, the interaction between $\beta$-catenin and NF- $\kappa B$ was analyzed using coimmunoprecipitation and colocalization experiments. Coimmunoprecipitation of $\beta$-catenin and NF- $\kappa B$ was elevated by LPS; however, it was significantly reduced by LGK974 treatment (Fig. 7a). Data for input samples used in the coimmunoprecipitation assays are shown in Fig. 7b. We also assessed the colocalization of $\beta$-catenin and NF- $\mathrm{KB}$ by confocal fluorescence microscopy of liver tissues (Fig. 7c). In saline-treated control mice, $\beta$-catenin and NF- $\mathrm{KB}$ did not colocalize $(R=-0.15)$; however, in endotoxemic mice, they $\operatorname{did}(R=0.69)$, and this colocalization was suppressed by LGK974 treatment $(R=0.07)$.

The interaction between $\beta$-catenin and NF- $\mathrm{KB}$ during endotoxemia or sepsis has not been defined to date, even 


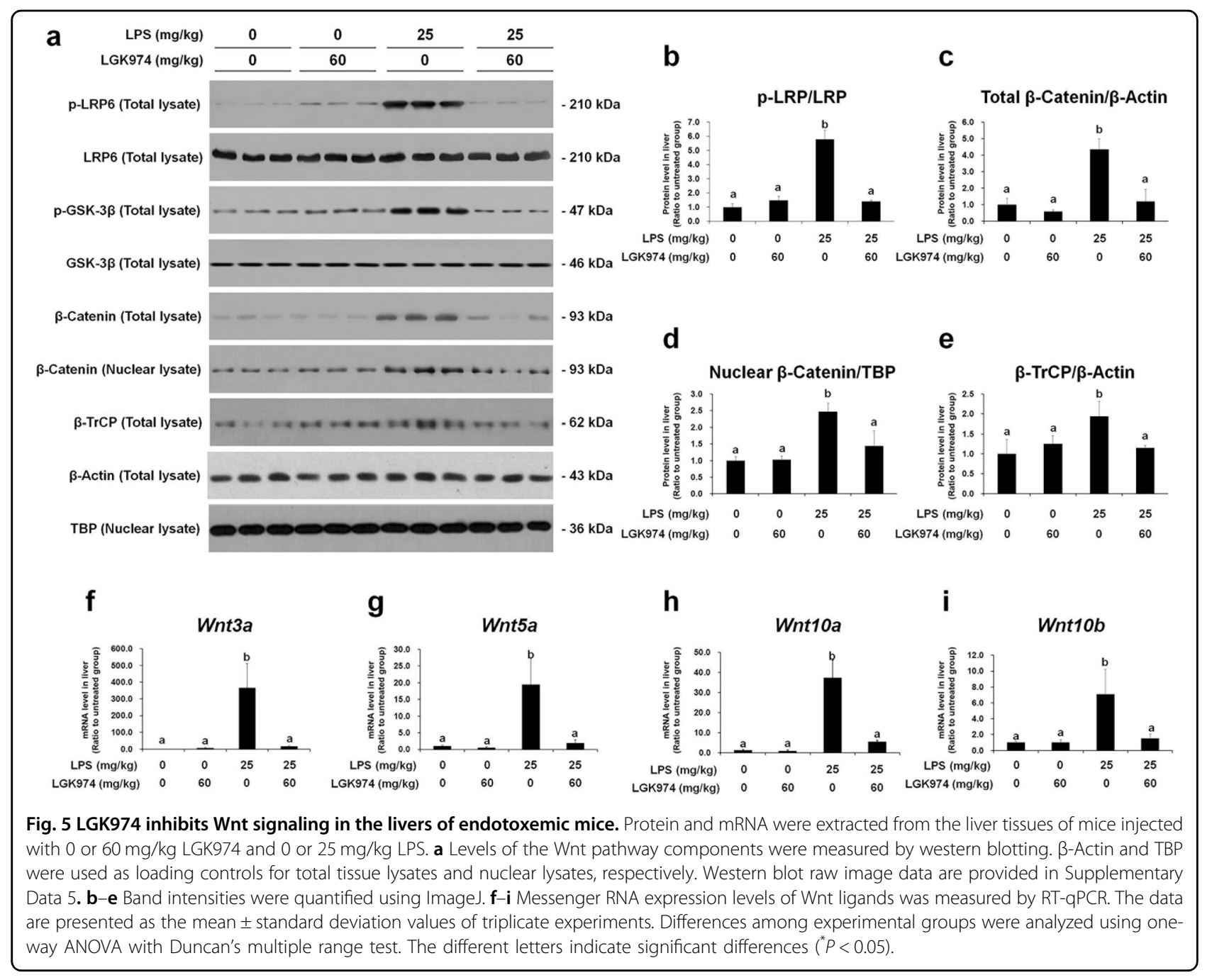

though recent studies have reported the existence of this interaction in other conditions. It has been reported that overexpression of $\beta$-catenin induces nuclear localization of NF- $\mathrm{kB}$ in cardiomyocytes during acute myocardial infarction $^{48}$. In contrast, depletion of $\beta$-catenin by siRNA reduces LPS-induced NF- $\mathrm{kB}$ activation in human bronchial epithelial cells ${ }^{49}$. However, it should be noted that the interaction between $\beta$-catenin and NF- $\mathrm{KB}$ is complex; $\beta$-catenin exerts not only a proinflammatory function by enhancing NF- $\mathrm{kB}$ activity but also an anti-inflammatory function by repressing it. It has been reported that $\beta$-catenin reduces NF- $\kappa B$ activity in human articular chondrocytes $^{50}$. The effect is often cell- and tissuedependent or stimulus-specific and needs to be investigated in a context-dependent manner ${ }^{51}$.

\section{LGK974 reduces liver damage in mice with LPS-induced endotoxemia}

We also found that the plasma levels of alanine aminotransferase (ALT) and aspartate aminotransferase
(AST), well-known markers of liver damage, were elevated by LPS and significantly reduced by LGK974 (Fig. 8a, b). In addition, LPS-induced pathological changes in liver tissue, such as necrosis and vacuolation of hepatocytes as well as infiltration of inflammatory cells, were suppressed by LGK974 treatment (Fig. 8c-f).

Recent studies have suggested the involvement of Wnt signaling in sepsis ${ }^{15}$. It was reported that the levels of multiple WNT ligands were increased in the peripheral blood of patients with septic shock as well as in splenic tissue of endotoxemic mice ${ }^{18}$. WNT5A levels were significantly increased in the sera of patients with sepsis ${ }^{17}$ and in lung biopsies from patients with septic acute respiratory distress syndrome ${ }^{52}$. iCRT3, a Wnt signaling inhibitor, reportedly decreased the plasma levels of proinflammatory cytokines and ameliorated lung injury in a mouse model of sepsis induced by cecal ligation and puncture ${ }^{16}$. However, the crosstalk between the Wnt/ $\beta$-catenin and NF- $\mathrm{kB}$ pathways has not been elucidated in sepsis. 


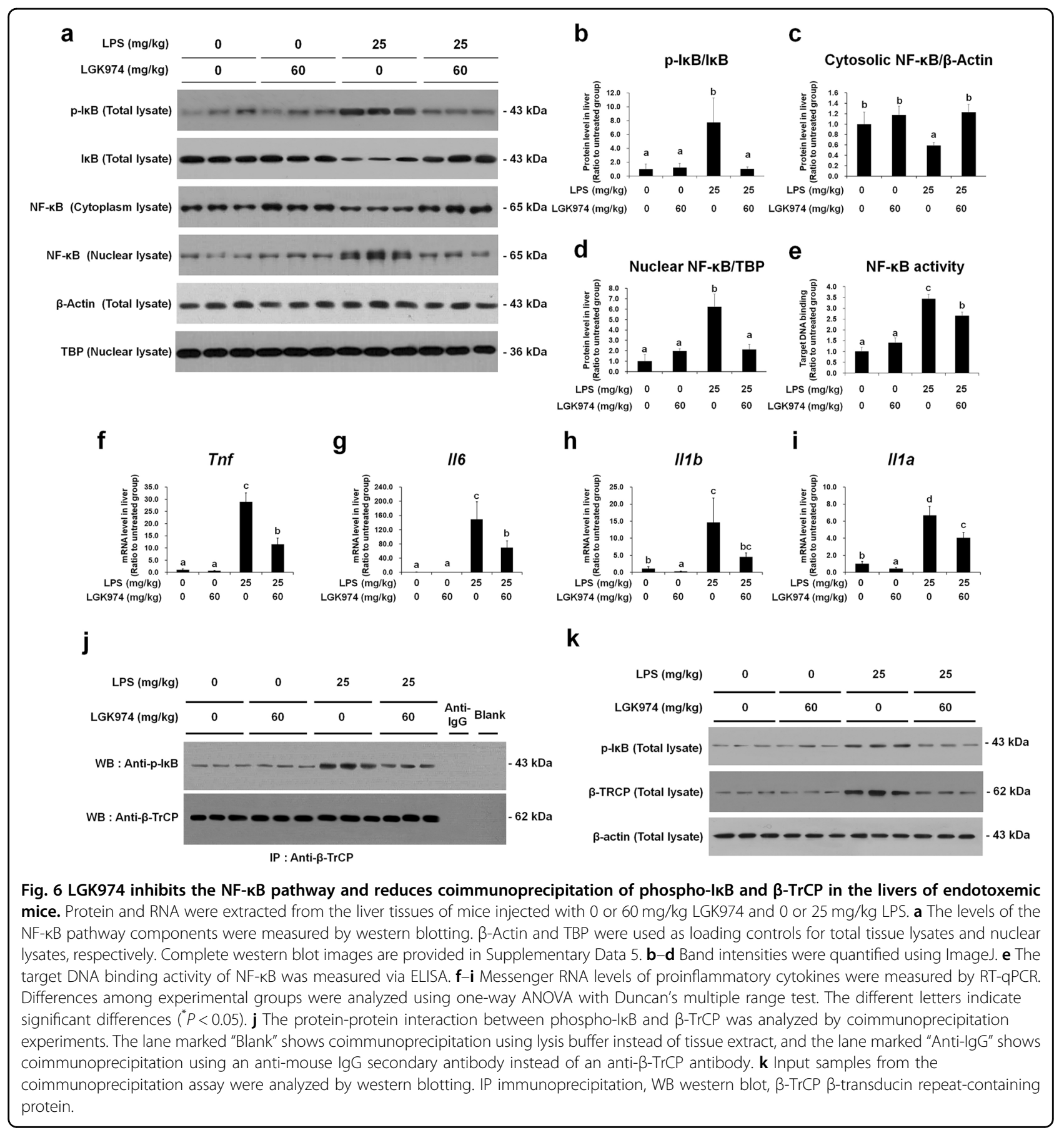

In this study, we identified crosstalk between two pathways in an animal model of sepsis. Our results strongly suggest that the crosstalk between the Wnt/ $\beta$-catenin and NF- $\mathrm{kB}$ pathways contributes to the mutual activation of these two pathways, which results in amplified proinflammatory cytokine production; damage to organs, including the liver; and death. LPS-induced NF- $\kappa B$ signaling may activate the Wnt pathway. Our results showed that the mRNA levels of Wnt ligands, including Wnt3a, Wnt5a, Wnt10a, and Wnt10b, correlated with the target DNA binding activity of NF- $\mathrm{KB}$ (Fig. $4 \mathrm{e}, \mathrm{j}-\mathrm{m}$ ), as the promoters of some Wnt ligands have binding sites for NF- $\mathrm{B}^{38-42}$. Wnt ligands, expressed by NF- $\kappa B$, activated Wnt signaling and increased the levels of both $\beta$-catenin and $\beta$-TrCP (Fig. 4q, r), subsequently enhancing their protein-protein interactions with NF- $\mathrm{kB}$ (Fig. 7a, c) and phospho-IкB (Fig. 6j), which in turn activated NF- $\mathrm{kB}$ signaling. 
a

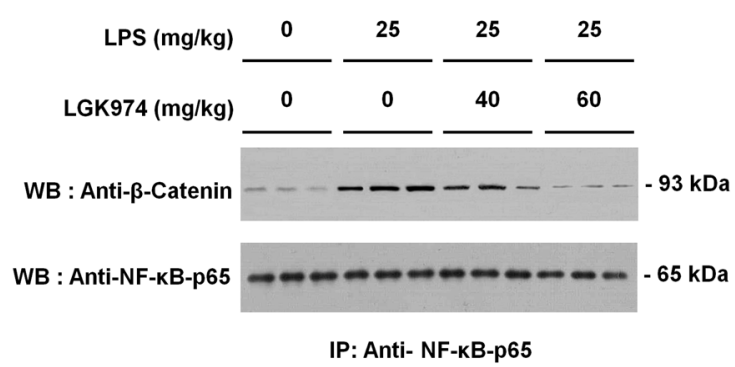

b

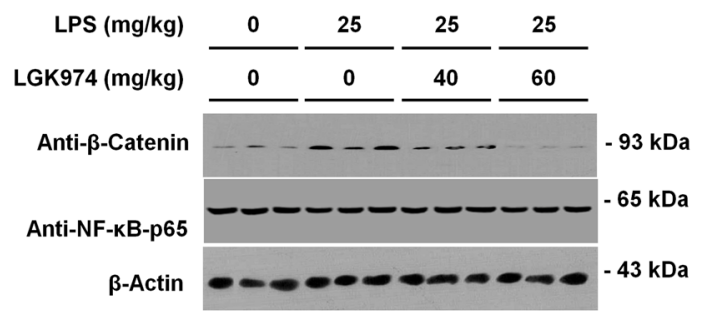

WB : Input

\section{C}
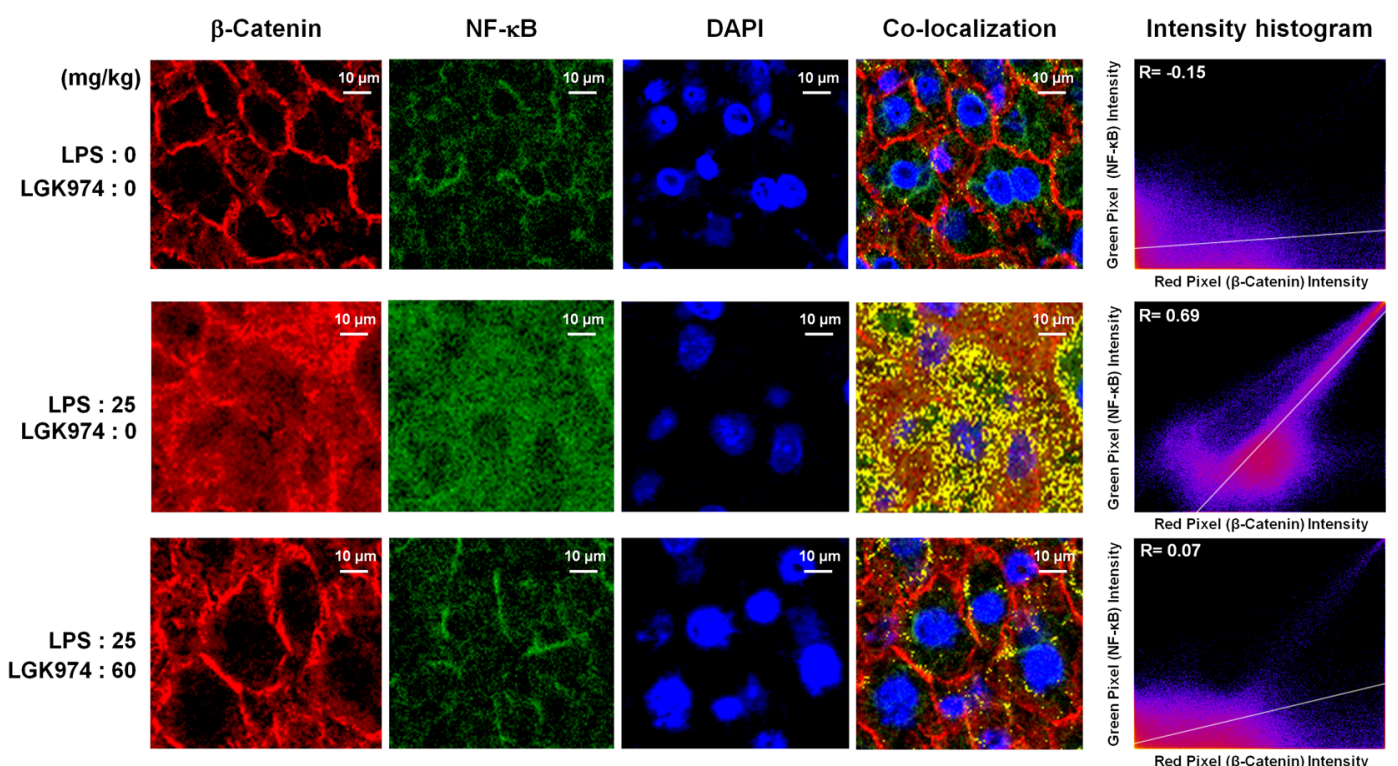

Fig. 7 LGK974 reduces the coimmunoprecipitation and colocalization of $\beta$-catenin and NF-KB in the liver tissues of endotoxemic mice. a, b Protein was extracted from the liver tissues of mice injected with 0, 40, or $60 \mathrm{mg} / \mathrm{kg} \mathrm{LGK974}$ and 0 or $25 \mathrm{mg} / \mathrm{kg}$ LPS. The protein-protein interaction between $\beta$-catenin and NF-KB p65 was analyzed by coimmunoprecipitation (a). Input samples from the coimmunoprecipitation assay were analyzed by western blotting (b). IP immunoprecipitation, WB western blot. c Images showing immunofluorescence staining for $\beta$-catenin and NF-KB and DAPI staining for nuclei. All images were acquired at a magnification of 600x using a Nikon Asia confocal system (Nikon, Tokyo, Japan). Images are representative of three experiments. Colocalization was quantified using ImageJ to calculate Pearson correlation coefficient $(R)$ values.

The findings of this study are summarized in Fig. 9. Our experimental data showed LPS-induced NF- $\mathrm{kB}$ signaling and Wnt ligand expression (red lines) as well as increased Wnt/ $\beta$-catenin signaling and interactions between $\beta$-catenin and NF- $\mathrm{KB}$ and between $\beta-\operatorname{TrCP}$ and $\mathrm{I} \kappa \mathrm{B}$ (blue lines). LGK974 exerts a suppressive effect on cytokine production by suppressing the upregulation of $\beta$-catenin and $\beta-\operatorname{TrCP}$ as well as their interactions with NF- $\mathrm{kB}$ and phospho-ІкB, respectively. Cytokine-induced NF-кB pathway activation during sepsis has been documented in previous studies (violet line) ${ }^{53}$.

We suggest that these interactions may occur in diverse cell types, including endothelial cells and macrophage-type cells in the liver. The liver is considered the main source of cytokine production during sepsis; Kupffer cells, which are macrophage-type cells in the liver, as well as natural killer cells, CD8 $+\mathrm{T}$ cells, endothelial cells, hepatic stellate cells, and hepatocytes, have been reported to participate in the production of proinflammatory cytokines during $\operatorname{sepsis}^{14}$. In our previous study, we showed that LGK974 suppressed proinflammatory cytokine production via modulation of the Wnt pathway in LPS-stimulated human endothelial cells ${ }^{29}$. Recently, we found that the protein-protein interaction between $\beta$-catenin and NF$\mathrm{B}$ was enhanced by LPS and reduced by LGK974 in RAW264.7 murine macrophage cells (unpublished observation). In this study, we did not analyze the types of cells in liver tissue, but various cell types, including endothelial cells and macrophage-type cells, may be 


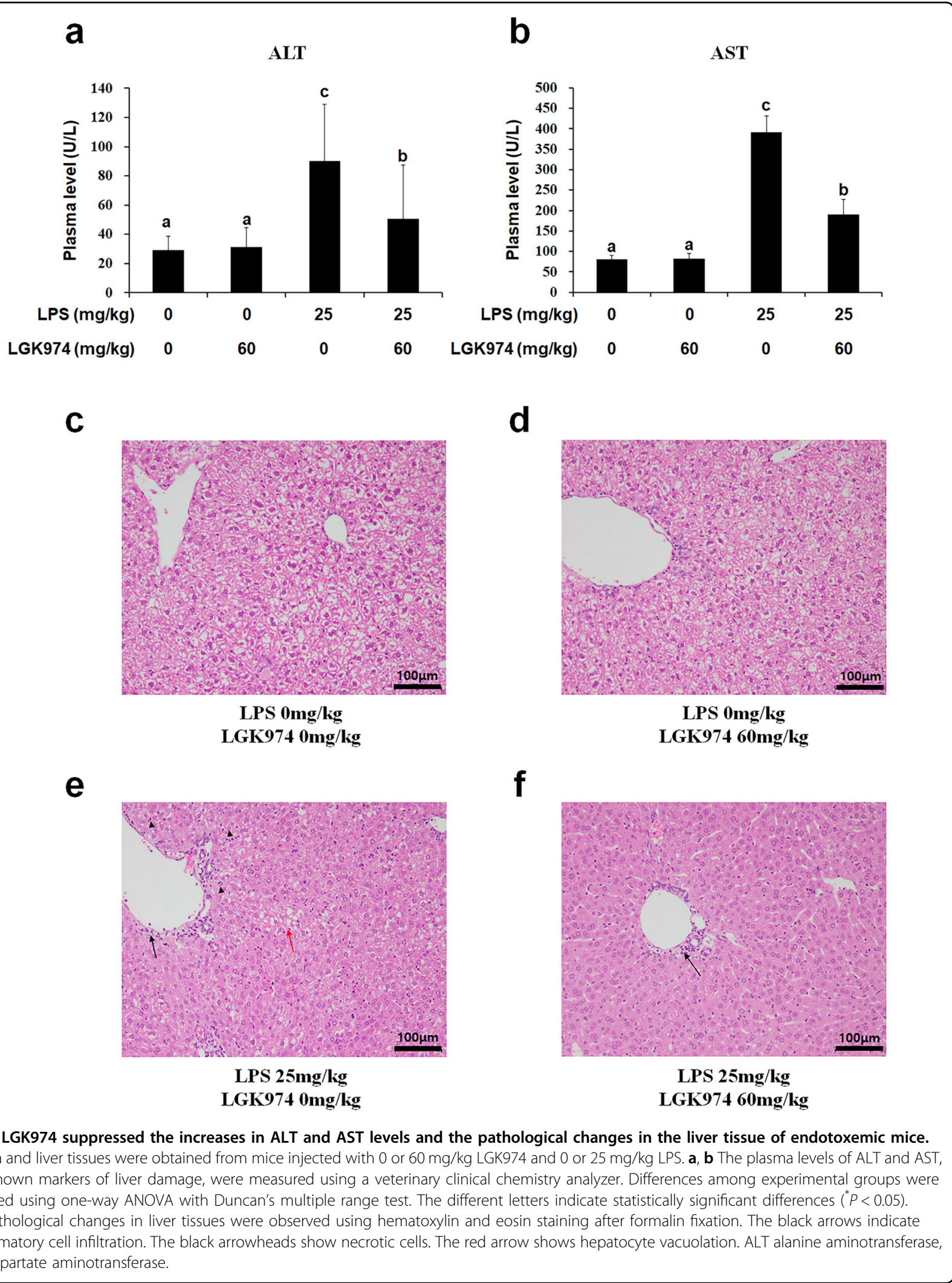




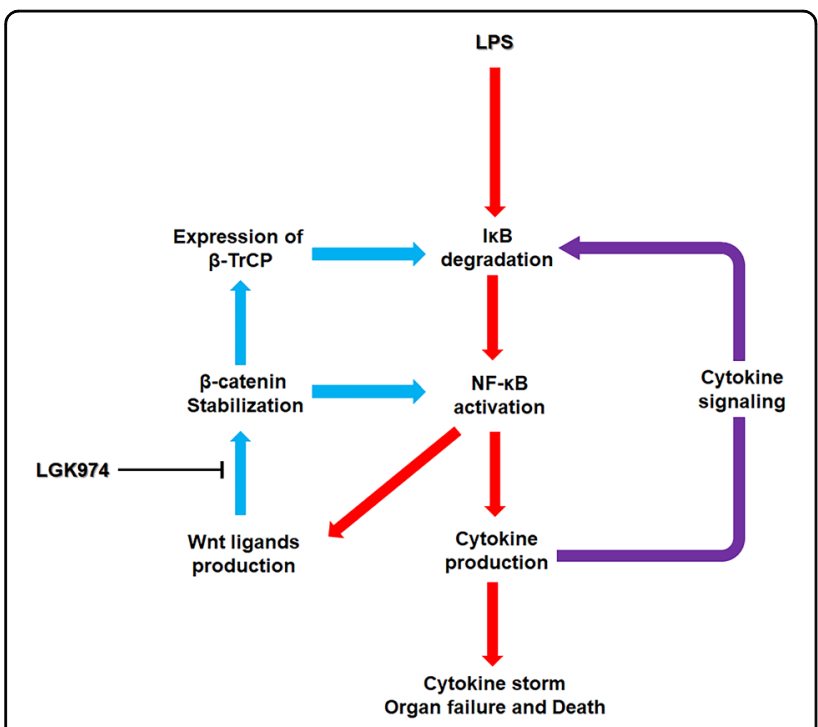

Fig. 9 Possible mechanism of the crosstalk between the Wnt/ $\beta$-catenin and NF-KB pathways during endotoxemia. The red arrows represent LPS-induced NF-KB signaling and Wnt ligand expression, and the blue arrows represent Wnt/ $\beta$-catenin signaling along with its crosstalk with NF-kB signaling, both of which were observed in this study. The violet arrow represents cytokine-induced NF-KB pathway activation, which has been reported in previous studies. LGK974 exerts a suppressive effect on endotoxemia by suppressing the upregulation of $\beta$-catenin and $\beta-\operatorname{TrCP}$ as well as their interactions with NF-KB and phospho-IKB, respectively.

involved in this process. Further study is necessary to confirm the results.

This study has some limitations. We primarily focused on liver dysfunction; thus, further studies are needed to analyze the effects on other organs, such as the lungs, heart, and kidneys. Furthermore, this study focused on the early phase of endotoxemia; most experiments were conducted using liver tissue and blood samples collected $6 \mathrm{~h}$ after LPS injection. Further studies are needed to analyze the time course and late phase of endotoxemia. The endotoxin and E. coli injection mouse models used in this study have been widely used for sepsis studies to date. As animal models of sepsis only partially recapitulate human sepsis, further studies employing more diverse animal models, including cecal ligation and puncture models, colon ascendent stent peritonitis models, pneumonia models, and implantation models, are needed ${ }^{10}$.

In conclusion, we demonstrated that the Wnt signaling inhibitor LGK974 downregulates proinflammatory cytokine production by modulating the crosstalk between the $\mathrm{Wnt} / \beta$-catenin and NF- $\mathrm{BB}$ pathways, thereby suppressing the induction of cytokine storm, liver damage, and lethality in mice with LPS-induced endotoxemia. Our data suggest that LGK974 may be a therapeutic candidate for endotoxemia and sepsis.

\section{Acknowledgements}

This research was supported by the Basic Science Research Program (2017R1D1A1B03029033 and 2020R1F1A1064537) of the National Research Foundation (NRF) of Korea. This work was also supported by the Basic Study and Interdisciplinary R\&D Foundation Fund of the University of Seoul (2019) to Eek-Hoon Jho. The authors thank eBiogen for assistance with the RNA-seq experiments.

\section{Author details}

'Department of Microbiology, Chung-Ang University College of Medicine, Seoul 06974, Republic of Korea. ${ }^{2}$ Department of Biochemistry, University of Washington, Seattle, WA 98195, USA. ${ }^{3}$ Department of Life Science, University of Seoul, Seoul 02504, Republic of Korea

\section{Conflict of interest}

The authors declare no competing interests.

\section{Publisher's note}

Springer Nature remains neutral with regard to jurisdictional claims in published maps and institutional affiliations.

Supplementary information The online version contains supplementary material available at https://doi.org/10.1038/s12276-021-00577-z.

Received: 5 August 2020 Revised: 13 January 2021 Accepted: 24 January 2021.

Published online: 10 March 2021

\section{References}

1. Danner, R. L. et al. Endotoxemia in human septic shock. Chest 99, 169-175 (1991).

2. Chong, D. L. \& Sriskandan, S. Pro-inflammatory mechanisms in sepsis. Contrib. Microbiol. 17, 86-107 (2011).

3. Chousterman, B. G., Swirski, F. K. \& Weber, G. F. Cytokine storm and sepsis disease pathogenesis. Semin. Immunopathol. 39, 517-528 (2017).

4. Singer, M. et al. The Third International Consensus Definitions for Sepsis and Septic Shock (Sepsis-3). J. Am. Med. Assoc. 315, 801-810 (2016).

5. Kamisoglu, K. et al. Human metabolic response to systemic inflammation: assessment of the concordance between experimental endotoxemia and clinical cases of sepsis/SIRS. Crit. Care 19, 71 (2015).

6. Bottiroli, M. et al. Prevalence and clinical significance of early high endotoxin activity in septic shock: an observational study. J. Crit. Care 41, 124-129 (2017).

7. Knotek, M. et al. Endotoxemic renal failure in mice: role of tumor necrosis factor independent of inducible nitric oxide synthase. Kidney Int. 59, 2243-2249 (2001).

8. Ahmad, A., Gero, D., Olah, G. \& Szabo, C. Effect of endotoxemia in mice genetically deficient in cystathionine-gamma-lyase, cystathionine-betasynthase or 3-mercaptopyruvate sulfurtransferase. Int. J. Mol. Med. 38, 1683-1692 (2016).

9. van der Meer, A. J. et al. Neutrophils mitigate the systemic host response during endotoxemia in mice. Immunology 156, 277-281 (2019).

10. Kingsley, S. M. \& Bhat, B. V. Differential paradigms in animal models of sepsis. Curr. Infect. Dis. Rep. 18, 26 (2016).

11. Wang, D., Yin, Y. \& Yao, Y. Advances in sepsis-associated liver dysfunction. Burns Trauma 2, 97-105 (2014).

12. Enayati, P., Brennan, M. F. \& Fong, Y. Systemic and liver cytokine activation. Implications for liver regeneration and posthepatectomy endotoxemia and sepsis. Arch. Surg. 129, 1159-1164 (1994).

13. Nesseler, N. et al. Clinical review: the liver in sepsis. Crit. Care 16, 235 (2012).

14. Yan, J., Li, S. \& Li, S. The role of the liver in sepsis. Int. Rev. Immunol. 33, 498-510 (2014).

15. Houschyar, K. S. et al. Role of Wnt signaling during inflammation and sepsis: a review of the literature. Int. J. Artif. Organs 41, 247-253 (2018).

16. Sharma, A., Yang, W. L., Ochani, M. \& Wang, P. Mitigation of sepsis-induced inflammatory responses and organ injury through targeting Wnt/beta-catenin signaling. Sci. Rep. 7, 9235 (2017). 
17. Schulte, D. M. et al. The wingless-related integration site-5a/secreted frizzledrelated protein-5 system is dysregulated in human sepsis. Clin. Exp. Immunol. 180, 90-97 (2015).

18. Gatica-Andrades, M. et al. WNT ligands contribute to the immune response during septic shock and amplify endotoxemia-driven inflammation in mice. Blood Adv. 1, 1274-1286 (2017).

19. Liu, J. et al. Targeting Wnt-driven cancer through the inhibition of Porcupine by LGK974. Proc. Natl Acad. Sci. USA 110, 20224-20229 (2013).

20. Boone, J. D. et al. Targeting the Wnt/beta-catenin pathway in primary ovarian cancer with the porcupine inhibitor WNT974. Lab. Investig. 96, 249-259 (2016).

21. Guimaraes, P. P. G. et al. Potent in vivo lung cancer Wnt signaling inhibition via cyclodextrin-LGK974 inclusion complexes. J. Control Release 290, 75-87 (2018).

22. Zimmerli, D. et al. WNT ligands control initiation and progression of human papillomavirus-driven squamous cell carcinoma. Oncogene 37, 3753-3762 (2018).

23. $\mathrm{Li}, \mathrm{H}$. et al. Therapeutic effects of antibiotic drug tigecycline against cervical squamous cell carcinoma by inhibiting Wnt/beta-catenin signaling. Biochem. Biophys. Res. Commun. 467, 14-20 (2015).

24. Kahlert, U. D. et al. Pharmacologic Wnt inhibition reduces proliferation, survival, and clonogenicity of glioblastoma cells. J. Neuropathol. Exp. Neurol. 74 889-900 (2015).

25. Suwala, A. K. et al. Inhibition of Wnt/beta-catenin signaling downregulates expression of aldehyde dehydrogenase isoform 3A1 (ALDH3A1) to reduce resistance against temozolomide in glioblastoma in vitro. Oncotarget $\mathbf{9}$ 22703-22716 (2018)

26. Picco, G. et al. Loss of AXIN1 drives acquired resistance to WNT pathway blockade in colorectal cancer cells carrying RSPO3 fusions. EMBO Mol. Med. 9 , 293-303 (2017).

27. Pai, S. G. et al. Wnt/beta-catenin pathway: modulating anticancer immune response. J. Hematol. Oncol. 10, 101 (2017).

28. Li, A. et al. Canonical Wnt inhibitors ameliorate cystogenesis in a mouse ortholog of human ADPKD. JCI Insight 3, e95874 (2018).

29. Jang, J., Jung, Y., Kim, Y., Jho, E. H. \& Yoon, Y. LPS-induced inflammatory response is suppressed by Wnt inhibitors, Dickkopf-1 and LGK974. Sci. Rep. 7, 41612 (2017).

30. Mayr, F. B., Yende, S. \& Angus, D. C. Epidemiology of severe sepsis. Virulence $\mathbf{5}$ 4-11 (2014)

31. Subramanian, A. et al. Gene set enrichment analysis: a knowledge-based approach for interpreting genome-wide expression profiles. Proc. Natl Acad. Sci. USA 102, 15545-15550 (2005).

32. Livak, K. J. \& Schmittgen, T. D. Analysis of relative gene expression data using real-time quantitative PCR and the 2(-Delta Delta $C(T)$ ) method. Methods $\mathbf{2 5}$ 402-408 (2001).

33. Bae, T. et al. Paeonia lactiflora root extract suppresses cancer cachexia by down-regulating muscular NF-kappaB signalling and muscle-specific E3 ubiquitin ligases in cancer-bearing mice. J. Ethnopharmacol. 246, 112222 (2020).

34. Iyer, S. S. \& Cheng, G. Role of interleukin 10 transcriptional regulation in inflammation and autoimmune disease. Crit. Rev. Immunol. 32, 23-63 (2012).

35. Carter, A. B., Monick, M. M. \& Hunninghake, G. W. Lipopolysaccharide-induced NF-kappaB activation and cytokine release in human alveolar macrophages is PKC-independent and TK- and PC-PLC-dependent. Am. J. Respir. Cell Mol. Biol. 18, 384-391 (1998).

36. Trede, N. S., Tsytsykova, A. V., Chatila, T., Goldfeld, A. E. \& Geha, R. S. Transcriptional activation of the human TNF-alpha promoter by superantigen in human monocytic cells: role of NF-kappa B. J. Immunol. 155, 902-908 (1995).

37. Spiegelman, V. S. et al. Wnt/beta-catenin signaling induces the expression and activity of betaTrCP ubiquitin ligase receptor. Mol. Cell 5, 877-882 (2000).

38. Ge, X. P. et al. Requirement of the NF-kappaB pathway for induction of Wnt-5A by interleukin-1 beta in condylar chondrocytes of the temporomandibular joint: functional crosstalk between the Wnt-5A and NF-kappaB signaling pathways. Osteoarthr. Cartil. 19, 111-117 (2011).

39. Blumenthal, A. et al. The Wingless homolog WNT5A and its receptor Frizzled-5 regulate inflammatory responses of human mononuclear cells induced by microbial stimulation. Blood 108, 965-973 (2006).

40. Zhang, Y. et al. Reciprocal requirements for EDA/EDAR/NF-kappaB and Wnt/ beta-catenin signaling pathways in hair follicle induction. Dev. Cell 17, 49-61 (2009).

41. Katula, K. S., Joyner-Powell, N. B., Hsu, C. C. \& Kuk, A. Differential regulation of the mouse and human Wnt5a alternative promoters A and B. DNA Cell Biol. 31, 1585-1597 (2012).

42. Katoh, M. \& Katoh, M. AP1- and NF-kappaB-binding sites conserved among mammalian WNT10B orthologs elucidate the TNFalpha-WNT10B signaling loop implicated in carcinogenesis and adipogenesis. Int. J. Mol. Med. 19, 699-703 (2007).

43. Spencer, E., Jiang, J. \& Chen, Z. J. Signal-induced ubiquitination of IkappaBalpha by the F-box protein Slimb/beta-TrCP. Genes Dev. 13, 284-294 (1999).

44. Winston, J. T. et al. The SCFbeta-TRCP-ubiquitin ligase complex associates specifically with phosphorylated destruction motifs in IkappaBalpha and betacatenin and stimulates IkappaBalpha ubiquitination in vitro. Genes Dev. 13 270-283 (1999).

45. Shirane, M., Hatakeyama, S., Hattori, K., Nakayama, K. \& Nakayama, K. Common pathway for the ubiquitination of IkappaBalpha, IkappaBbeta, and IkappaBepsilon mediated by the F-box protein FWD1. J. Biol. Chem. 274 28169-28174 (1999).

46. Wang, X., Adhikari, N., Li, Q., Guan, Z. \& Hall, J. L. The role of [beta]-transducin repeat-containing protein ([beta]-TrCP) in the regulation of NF-[kappa]B in vascular smooth muscle cells. Arterioscler. Thromb. Vasc. Biol. 24, 85-90 (2004).

47. Cadigan, K. M. \& Liu, Y. I. Wht signaling: complexity at the surface. J. Cell Sci. 119, 395-402 (2006).

48. Lin, J. C. et al. beta-Catenin overexpression causes an increase in inflammatory cytokines and NF-kappaB activation in cardiomyocytes. Cell Mol. Biol. 63, 17-22 (2016).

49. Jang, J., Ha, J. H., Chung, S. I. \& Yoon, Y. Beta-catenin regulates NF-kappaB activity and inflammatory cytokine expression in bronchial epithelial cells treated with lipopolysaccharide. Int. J. Mol. Med. 34, 632-638 (2014).

50. Ma, B., van Blitterswijk, C. A. \& Karperien, M. A Wnt/beta-catenin negative feedback loop inhibits interleukin-1-induced matrix metalloproteinase expression in human articular chondrocytes. Arthritis Rheum. 64, 2589-2600 (2012).

51. Ma, B. \& Hottiger, M. O. Crosstalk between Wnt/beta-Catenin and NF-kappaB signaling pathway during inflammation. Front. Immunol. 7, 378 (2016).

52. Villar, J. et al. Early activation of pro-fibrotic WNT5A in sepsis-induced acute lung injury. Crit. Care 18, 568 (2014).

53. Liu, S. F. \& Malik, A. B. NF-kappa B activation as a pathological mechanism of septic shock and inflammation. Am. J. Physiol. Lung Cell Mol. Physiol. 290, L622-L645 (2006). 